\title{
PASSIVE COOLING OF ELECTRONIC COMPONENTS USING CLOSED ALUMINIUM HOUSING FILLED WITH LIQUID
}

\author{
Janis Galins, Aigars Laizans, Ainars Galins \\ Latvia University of Life Sciences and Technologies, Latvia \\ janis.galins@1lu.lv, aigars.laizans@1lu.lv, ainars.galins@1lu.lv
}

\begin{abstract}
The use of digital data transmission equipment has increased rapidly in recent years. There is a need for more powerful, more compact equipment that can deliver the required data transfer intensity. More powerful processors and radio signal transmission circuits require more power, and the energy losses are emitted as increasing heat flux, bringing in substantial risks of equipment overheating, thus reducing the device's reliability and causing overall faults of the devices. Aggressive environmental conditions are common in the bioeconomy product processing industries, and the devices used often suffer from inappropriate design of cooling solutions, including both active and passive systems. The electronic devices require airtight design, which protects from extensive moisture and corrosive gases. Passive cooling solutions are more reliable and do not consume any energy, but they have less heat transfer capacity than active cooling. Efficient solution could be passive cooling with convection, if the inside of the unit's body is filled with dielectric fluid such as oil. The study carries out heat transfer and fluid flow simulations in the electronic device to show how the heat flow dissipates in the environment using passive cooling design. Convection and conduction efficiency is analysed to find a way to implement a technical solution for new product development. As a result of the study, it has been found that the closed housing heatsink does not protect the component from overheating, if the air inside the housing is a heat transfer fluid. The use of heat bridges or filling the inside of the casing with a dielectric heat transfer fluid was more efficient. The studies have shown that semiconductors can be effectively cooled using liquid heat transfer fluids, such as ester MIDEL 7131.
\end{abstract}

Keywords: cooling system, heat modelling, heat transfer, heat convection.

\section{Introduction}

The housing of majority of electrical equipment has air inside, making it easier to repair and replace the damaged electronic elements, but heat transfer through the convection is not effective enough. The industrially used airtight housing design sometimes includes filling the casing with polyurethane, but the polyurethane acts as a thermal insulation and the convection inside is reduced. Passive cooling solutions are more reliable and do not consume any energy, but they have less heat transfer capacity than active cooling. Efficient solution could be passive cooling with convection, if the inside of the unit's body is filled with a dielectric fluid. Different types of insulating fluids are used for cooling applications. Heat from the hot components is dissipated in the environment by convection. This technology is already used for cooling high power transformers. Research studies indicate that the cooling capacity of the alternative liquid worsens with aging due to the exponential decrease of the viscosity with temperature [1]. Synthetic ester ages considerably slower than the natural ester dielectric fluid and mineral oil under the same aging conditions [2]. Heat transfer efficiency is greatly influenced by the thermal conductivity, specific thermal conductivity, viscosity and the expansion coefficient of the heat transfer fluid.

As the liquid heats up, the viscosity decreases, thereby increasing the fluid flow rate and cooling efficiency [3-5]. Other research studies show that the maximum temperatures of natural ester - filled transformers are only several degrees higher than those in mineral oil - filled transformers [6-8]. The thermal properties of insulating fluids are shown in Table 1.

The higher viscosity of the natural ester fluid is partly compensated by better thermal conductivity. Syntheticester MIDEL 7131is a widespread and tested dielectric coolant.It is designed to provide an alternative to mineral oil, silicone liquid and dry-type transformers. The main benefits of MIDEL 7131 are described below.The high fire point of $316^{\circ} \mathrm{C}$ significantly increases the fire safety and reduces the need for fire protection equipment. Ester MIDEL 7131 is biodegradable in nature, thus reducing the risk of contamination if leakage occurs. MIDEL 7131 can be an effective solution in colder climates due to low pour point of $-56^{\circ} \mathrm{C}$.Perfectly suited for non-free-breathing and freebreathing applications due to its excellent stability of oxidation $[1 ; 2]$. 
Thermal properties of insulating fluids [6;9]

Table 1

\begin{tabular}{|c|c|c|c|}
\hline Property & Mineral oil & Natural esters & Synthetic esters \\
\hline Thermal conductivity at $20^{\circ} \mathrm{C}, \mathrm{W} \cdot(\mathrm{m} \cdot \mathrm{K})^{-1}$ & 0.126 & $0.160-0.167$ & 0.144 \\
\hline Specific heat in $20^{\circ} \mathrm{C}, \mathrm{J} \cdot(\mathrm{kg} \cdot \mathrm{K})^{-1}$ & 1860 & $1883-1943$ & 1880 \\
\hline Thermal expansion coefficient, ${ }^{\circ} \mathrm{C}^{-1}$ & 0.00075 & $0.00068-0.00074$ & 0.00075 \\
\hline Kinematic viscosity at $0^{\circ} \mathrm{C}, \mathrm{mm}^{2} \cdot \mathrm{s}^{-1}$ & 37.5 & $207-276$ & 240 \\
\hline Kinematic viscosity at $20^{\circ} \mathrm{C}, \mathrm{mm}^{2} \cdot \mathrm{s}^{-1}$ & 22 & $78-97$ & 70 \\
\hline Kinematic viscosity at $40^{\circ} \mathrm{C}^{-1} \mathrm{~mm}^{2} \cdot \mathrm{s}^{-1}$ & 9 & $36-42$ & 28 \\
\hline Kinematic viscosity at $100^{\circ} \mathrm{C}, \mathrm{mm}^{2} \cdot \mathrm{s}^{-1}$ & 2.6 & $8-9$ & 8 \\
\hline Density in $20^{\circ} \mathrm{C}, \mathrm{kg} \cdot \mathrm{m}^{-3}$ & 880 & $910-920$ & 970 \\
\hline
\end{tabular}

\section{Materials and methods}

The study uses a hermetic electrical device that is intended to be placed under aggressive environmental conditions. Inside the enclosure a semiconductor is placed on the PCB and emits a certain amount of heat. Passive cooling is used, because the fan is not allowed. Computational fluid dynamics (CFD) and heat transfer simulations were performed in Solidworks software. Only conduction and convection without radiation were used for heat transfer. The structure of the simulation model is shown in Fig. 1.

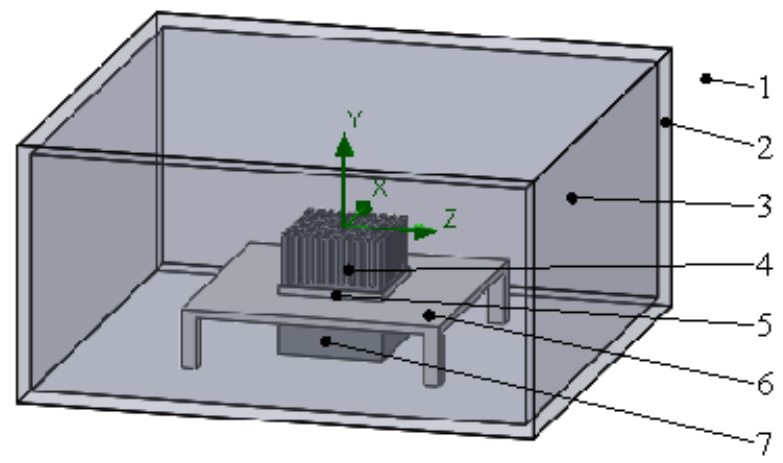

Fig. 1. Structure of simulation model: 1 - ambient air; 2 - enclosure; 3 - internal fluid; 4 - heatsink; 5 - semiconductor; 6 - printed circuit board; 7 - heat bridge

The ambient air with the temperature of $293.2 \mathrm{~K}$ is around theenclosure. Passive cooling solutions with heatsinks, heat bridges and liquid cooling with synthetic esterMIDEL 7131 have been tested to determine the most efficient. The solutions were compared both with dynamic changes in the temperature and with increasing the amount of heat generation from 1 to $10 \mathrm{~W}$.There was a need to create a new digital fluid for simulations using the thermal properties of synthetic esterMIDEL 7131, as shown in Table 2.

Table 2

Thermal properties of synthetic esterMIDEL 7131 over temperature range [6]

\begin{tabular}{|c|c|c|c|c|c|c|}
\hline $\begin{array}{c}\text { Temp- } \\
\text { erature, } \\
{ }^{\circ} \mathrm{C} \\
\end{array}$ & $\begin{array}{l}\text { Temp- } \\
\text { erature, } \\
{ }^{\circ} \mathbf{K} \\
\end{array}$ & $\begin{array}{l}\text { Kinematic } \\
\text { viscosity, } \\
\mathrm{mm}^{2} \cdot \mathrm{s}^{-1} \\
\end{array}$ & $\begin{array}{c}\text { Specific } \\
\text { heat, } \\
\mathbf{J} \cdot(\mathbf{k g} \cdot \mathbf{K})^{-1} \\
\end{array}$ & $\begin{array}{c}\text { Density, } \\
\text { kg }^{-3}{ }^{-3}\end{array}$ & \begin{tabular}{|c|} 
Thermal \\
conductivity, \\
$\mathbf{W} \cdot(\mathbf{m} \cdot \mathbf{K})^{-1}$ \\
\end{tabular} & \begin{tabular}{|c|}
$\begin{array}{c}\text { Coeff. of thermal } \\
\text { expansion, } \\
\mathbf{1} \cdot \mathbf{K}^{-1}\end{array}$ \\
\end{tabular} \\
\hline-30 & 243.15 & 4200 & 1783 & 1007 & 0.145 & 0.00072 \\
\hline-20 & 253.15 & 1400 & 1797 & 1000 & 0.145 & 0.00073 \\
\hline-10 & 263.15 & 430 & 1811 & 992 & 0.145 & 0.00074 \\
\hline 0 & 273.15 & 240 & 1830 & 985 & 0.145 & 0.00074 \\
\hline 10 & 283.15 & 125 & 1855 & 978 & 0.145 & 0.00075 \\
\hline 20 & 293.15 & 70 & 1880 & 970 & 0.144 & 0.00075 \\
\hline 30 & 303.15 & 43 & 1910 & 963 & 0.144 & 0.00076 \\
\hline 40 & 313.15 & 28 & 1933 & 956 & 0.143 & 0.00077 \\
\hline 50 & 323.15 & 19.5 & 1959 & 948 & 0.142 & 0.00077 \\
\hline
\end{tabular}


Table 2 (continued)

\begin{tabular}{|c|c|c|c|c|c|c|}
\hline $\begin{array}{l}\text { Temp- } \\
\text { erature, } \\
{ }^{\circ} \mathrm{C}\end{array}$ & $\begin{array}{l}\text { Temp- } \\
\text { erature, } \\
{ }^{0} \mathbf{K}\end{array}$ & $\begin{array}{l}\text { Kinematic } \\
\text { viscosity, } \\
\mathrm{mm}^{2} \cdot \mathrm{s}^{-1}\end{array}$ & $\begin{array}{l}\text { Specific } \\
\text { heat, } \\
\mathbf{J} \cdot(\mathbf{k g} \cdot \mathbf{K})^{-1}\end{array}$ & $\begin{array}{c}\text { Density, } \\
\mathbf{k g} \cdot \mathbf{m}^{-3}\end{array}$ & \begin{tabular}{|c|} 
Thermal \\
conductivity, \\
$\mathbf{W} \cdot(\mathbf{m} \cdot \mathbf{K})^{-1}$
\end{tabular} & $\begin{array}{c}\text { Coeff. of thermal } \\
\text { expansion, } \\
1 \cdot \mathrm{K}^{-1}\end{array}$ \\
\hline 60 & 333.15 & 14 & 1994 & 941 & 0.141 & 0.00078 \\
\hline 70 & 343.15 & 10.5 & 2006 & 934 & 0.140 & 0.00078 \\
\hline 80 & 353.15 & 8 & 2023 & 926 & 0.139 & 0.00079 \\
\hline 90 & 363.15 & 6.5 & 2040 & 919 & 0.137 & 0.00079 \\
\hline 100 & 373.15 & 5.25 & 2058 & 912 & 0.136 & 0.0008 \\
\hline
\end{tabular}

Dynamic viscosity, specific heat, density, thermal conductivity vary depending on the temperature, so the graphs are used in the simulations. Solidworks flow simulations require dynamic viscosity, so calculations were made:

$$
\mu=\rho \cdot v,
$$

where $\mu$-dynamic viscosity, Pa·s;

$\rho$ - density, $\mathrm{kg} \cdot \mathrm{m}^{-3}$;

$v$ - kinematic viscosity, $\mathrm{mm}^{2} \cdot \mathrm{s}^{-1}$.

Kinematic viscosity alsodepends on the temperature, as shown in Table 2. After the calculation the obtained graph is shown in Fig. 2.

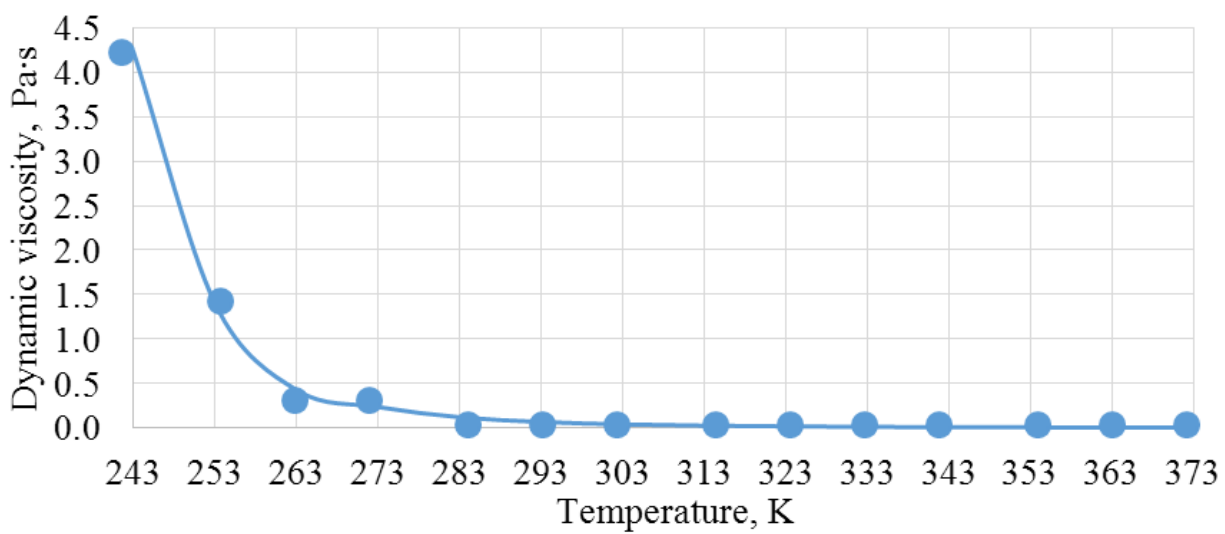

Fig. 2. Dynamic viscosity of ester MIDEL 7131 depending on temperature

Temperature fluctuations have a significant impact on the viscosity of the synthetic ester and the obtained graph is non-linear. The density graph and specific heat graph are linear, but the thermal conductivity does not change a lot depending on the temperature.

Input data were selected according to the model equipment and environmental conditions, as shown in Table 3.

Input data for CFD and heat transfer simulations

Table 3

\begin{tabular}{|c|c|c|}
\hline Parameter & Value & Unit \\
\hline Gravity in y axis direction & -9.81 & $\mathrm{~m} \cdot \mathrm{s}^{-2}$ \\
\hline Atmospheric pressure & 101325 & $\mathrm{~Pa}$ \\
\hline Ambient temperature & 293.2 & $\mathrm{~K}$ \\
\hline $\begin{array}{c}\text { Heat generation rate for } \\
\text { semiconductor }\end{array}$ & $1 \ldots 10$ & $\mathrm{~W}$ \\
\hline Fluids type & $\begin{array}{c}\text { Air; Ester MIDEL } \\
7131\end{array}$ \\
\hline
\end{tabular}

The simulation results are significantly influenced by the selected solid materials, because each of them has a different thermal conductivity. The selected solid materials are shown in Table 4. 
Solid materials used for CFD and heat transfer simulations

\begin{tabular}{|c|c|c|c|}
\hline Part & Size, $\mathbf{m m}$ & Material & $\begin{array}{c}\text { Thermal conductivity, } \\
\mathbf{W} \cdot(\mathbf{m} \cdot \mathbf{K})^{-1}[10]\end{array}$ \\
\hline Semiconductor & $20 \times 20 \times 1.5$ & Silicon & $\begin{array}{l}\sim 150 \text { (depends on } \\
\text { temperature) }\end{array}$ \\
\hline Printed circuit board (PCB) & $50 \times 50 \times 1.6$ & Laminate FR4 & 0.3 \\
\hline Enclosure & $\begin{array}{l}\text { 100x100x50 (wall } \\
\text { thickness } 2 \mathrm{~mm})\end{array}$ & \multirow{3}{*}{ Aluminium } & \multirow{3}{*}{$\begin{array}{l}\text { 237 (depends on } \\
\text { temperature) }\end{array}$} \\
\hline Heatsink & $20 \times 20 \times 10$ & & \\
\hline Heat bridge & $20 \times 20 \times 10$ & & \\
\hline
\end{tabular}

\section{Results and discussion}

Computational fluid dynamics (CFD) and heat transfer simulations were performed until the system reaches a steady-state. The research was done to state how the maximal temperature of the semiconductor depends on the heat generation rate. The results are shown in Fig. 3.

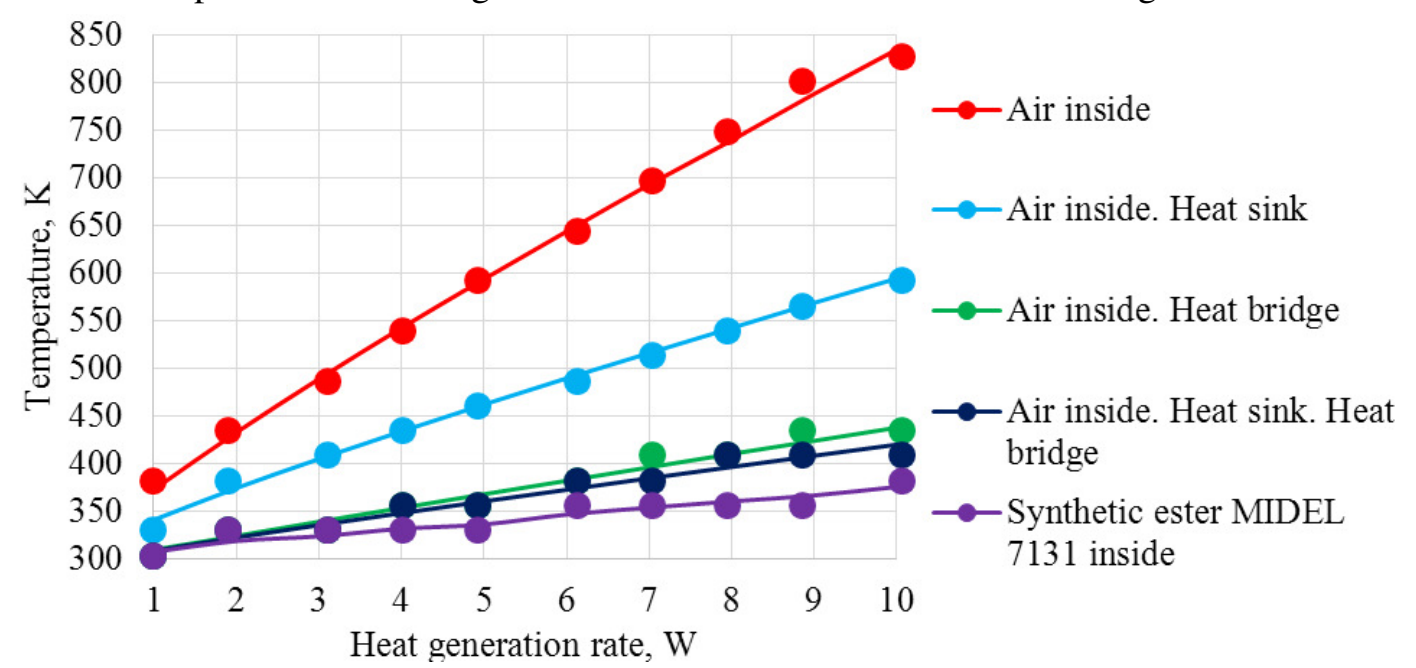

Fig. 3. Max temperature of semiconductor depending on heat generation rate

The "Air inside" curve represents the max temperature of the semiconductor depending on the heat generation rate, if no cooling solution is used. The "Air inside; Heat sink" represents a solution, when a heatsink is attached to the semiconductor and the internal fluid is air. Obviously, the most efficient solution is, when an internal fluid is esterMIDEL 7131.The obtained max temperature differences of the semiconductor were compared depending on the heat generation rate. Calculations have revealed how much the liquid cooling solution is better than the others, as shown in Table 5.

Semiconductor parts are most often specified for use in the "commercial" 0 to $70{ }^{\circ} \mathrm{C}(273.15$ to $343.15 \mathrm{~K})$ andin the "industrial" -40 to $85^{\circ} \mathrm{C}(233.15$ to $358.15 \mathrm{~K})$ operating temperature range[11].Manufacturers specify even higher safe operating temperatures.Graphics processing unit(GPU) such as Nvidia GTX 980 can exceedthe maximum safe temperature of $98^{\circ} \mathrm{C}(371.15 \mathrm{~K})$, as specified in the specification of the manufacturer[12].If the normal operating temperature of the semiconductor is $340 \mathrm{~K}$, cooling with ester MIDEL 7131 is $48 \%$ more efficient than cooling with the heatsink or $12 \%$ more efficient than cooling with the heat bridge. Better heat transfer results could be obtained by using mineral oil due to its lower viscosity.

Dynamic CFD and heat transfer simulation of the semiconductor with heat generation $5 \mathrm{~W}$ was performed. The resulting heating curve of max temperature of the semiconductor shown in Fig. 4.

Most of electronic components must not exceed $120^{\circ} \mathrm{C}(393.15 \mathrm{~K})$ operating temperatures. The graph shows that without cooling ("Air inside" curve) the maximum semiconductor temperature will exceed $393 \mathrm{~K}$ after $44 \mathrm{~s}$ and continues to increase damaging the semiconductor. The passive cooling solution with the heatsink only works for a short time, because after $57 \mathrm{~s}$ it is more efficient to have a 
heat bridge solution, but after $131 \mathrm{~s}$ the semiconductor temperature also will exceed $393 \mathrm{~K}$. The solution with a heat bridge or liquid fluid can prevent overheating in this case. The best long time solution is cooling with ester MIDEL 7131.It surpasses cooling with a heatsink after $27 \mathrm{~s}$.

Table 5

\section{Comparison of different passive cooling solutions}

\begin{tabular}{|c|c|c|c|c|}
\hline \multirow{2}{*}{$\begin{array}{c}\text { Heat } \\
\text { generati }\end{array}$} & \multirow{2}{*}{$\begin{array}{c}\text { Max temperature } \\
\text { of semiconductor, } \\
\text { on rate, } \\
\text { W }\end{array}$} & \multicolumn{4}{|c|}{$\begin{array}{c}\text { Cooling with ester MIDEL 7131 is better than other } \\
\text { solution, \% }\end{array}$} \\
\cline { 4 - 5 } 7131 is applied, K & $\begin{array}{c}\text { Air inside; } \\
\text { Heat sink }\end{array}$ & $\begin{array}{c}\text { Air inside; } \\
\text { Heat bridge }\end{array}$ & $\begin{array}{c}\text { Air inside; Heat } \\
\text { sink; Heat bridge }\end{array}$ \\
\hline 1 & 306.9 & 51 & 4 & 2 \\
\hline 2 & 318.4 & 49 & 5 & 3 \\
\hline 3 & 323.3 & 49 & 9 & 7 \\
\hline 4 & 331.3 & 48 & 10 & 8 \\
\hline 5 & 335.8 & 48 & 12 & 9 \\
\hline 6 & 346.2 & 48 & 12 & 9 \\
\hline 7 & 353.5 & 48 & 12 & 10 \\
\hline 8 & 360.1 & 48 & 13 & 10 \\
\hline 9 & 366.3 & 48 & 14 & 10 \\
\hline 10 & 375.2 & 48 & 14 & \\
\hline
\end{tabular}
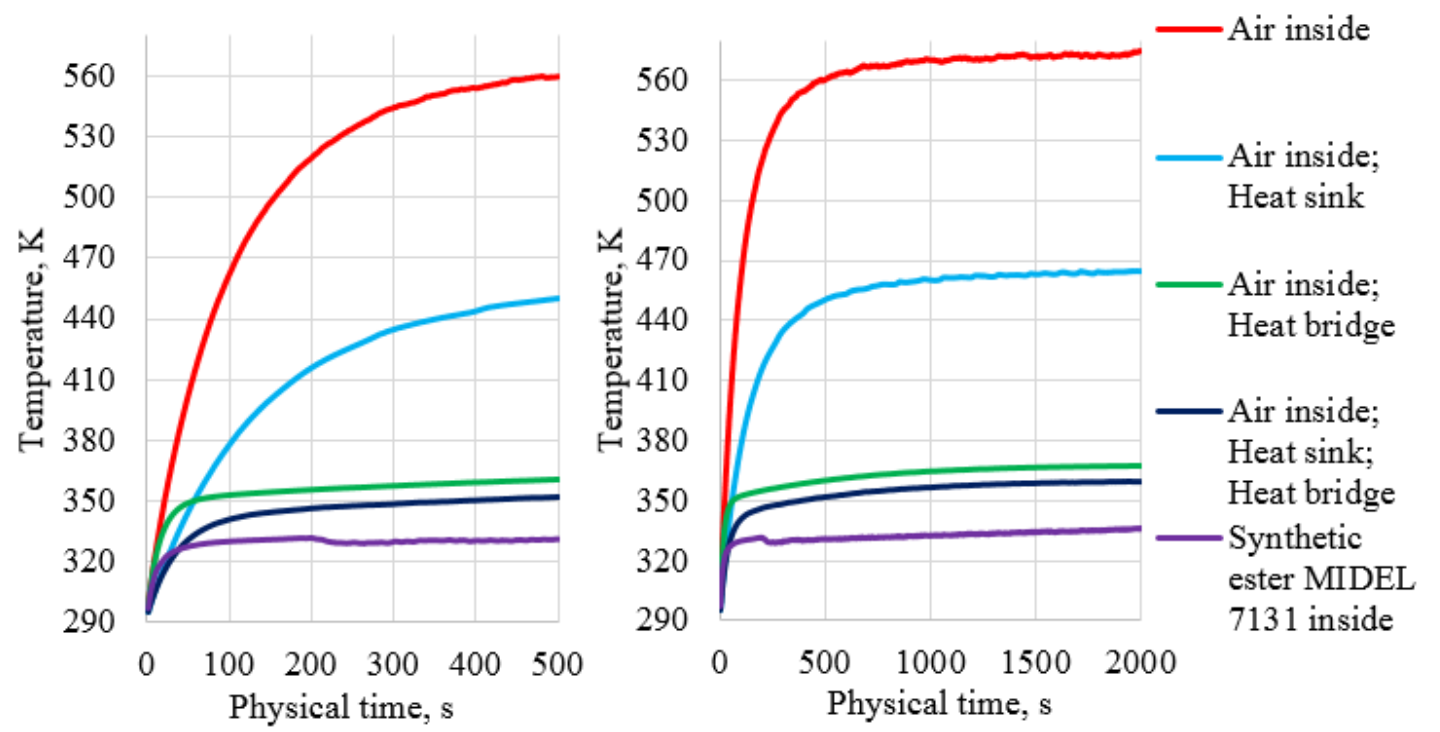

Fig. 4. Heating curve of max temperature of semiconductor with heat generation $5 \mathrm{~W}$

The dynamics of the heat transfer fluid was studied in time. Different distribution of the fluid temperature was observed after $50 \mathrm{~s}$ and $2000 \mathrm{~s}$, as shown in Fig. 5.

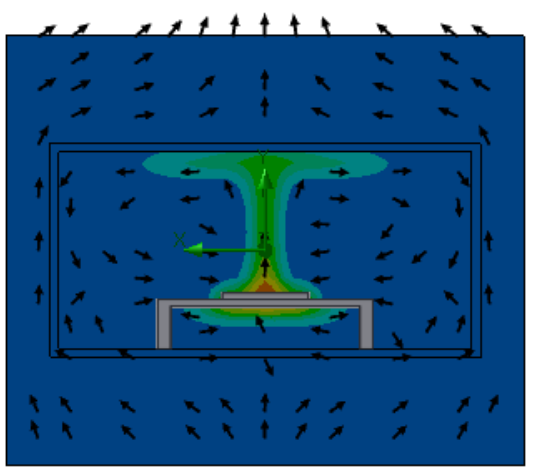

a)

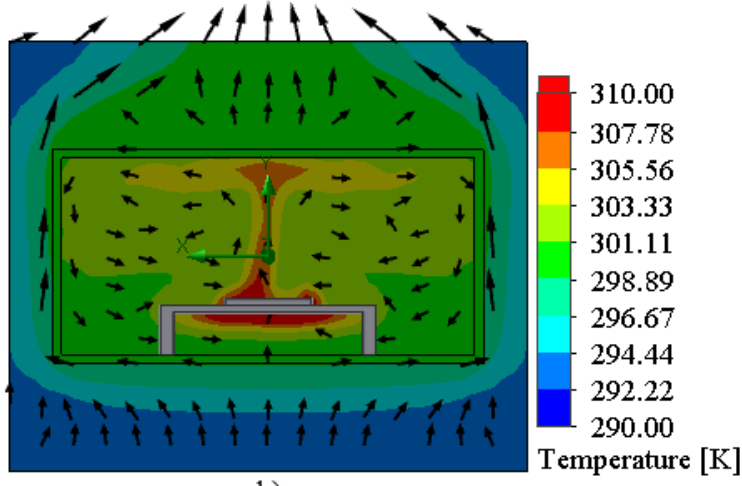

b)

Fig. 5. Temperatureof heat transfer fluid (ester MIDEL 7131 inside; air outside)in time with semiconductor heat generation $5 \mathrm{~W}$ : a - after $50 \mathrm{~s}$; b - after $2000 \mathrm{~s}$ 
The efficiency of the applied liquid heat transfer fluid depends on the working temperature. If the temperature rises, the viscosity decreases and the heat transfer improves. As the system stabilizes, the liquid fluid velocity decreases due to the decrease of the density difference. The temperature of the semiconductor in a particular enclosure reached its maximum $335.8 \mathrm{~K}$ after $2000 \mathrm{~s}$ with esterMIDEL 7131 applied.

\section{Conclusions}

1. Studies have shown that semiconductors can be effectively cooled using liquid heat transfer fluids, such as esterMIDEL 7131.

2. Cooling with ester MIDEL 7131in a particular enclosure is $48 \%$ more efficient than cooling with the heatsink or $12 \%$ more efficient than cooling with the heat bridge.

3. The temperature of the semiconductor in a particular enclosure reached its maximum $335.8 \mathrm{~K}$ after $2000 \mathrm{~s}$ with esterMIDEL 7131 applied.

4. The efficiency of the applied liquid heat transfer fluid depends on the working temperature due to the viscosity, but as the system stabilizes, the liquid fluid velocity decreases due to the decrease of the density difference.

5. The passive cooling solution with the heatsink only works for a very short time, thus heat bridges or liquid cooling should be used for long time periods.

\section{References}

[1] Ortiz A., Delgado F., Ortiz F. etc. The aging impact on the cooling capacity of a natural ester used in power transformers. Applied Thermal Engineering, vol. 144, 2018, pp. 797-803.

[2] Fofana I., Bouaïcha A., Farzaneh M. etc. Ageing behaviour of mineral oil and ester liquids: A comparative study. Annual Report - Conference on Electrical Insulation and Dielectric Phenomena, CEIDP, 2014, pp. 87-90.

[3] Hasan M. I. Improving the cooling performance of electrical distribution transformer using transformer oil - Based MEPCM suspension. Engineering Science and Technology, an International Journal, vol. 20, 2017, pp. 502-510.

[4] Hua H., Mingqiu D., Nannan W. etc. Three Dimensional Simulation Technology Research of Split Type Cooling Transformer Based on Finite Volume Method. Energy Procedia, vol. 141, 2017, pp. 405-410.

[5] Chereches N. C., Chereches M., Miron L. etc. Numerical Study of Cooling Solutions Inside a Power Transformer. Energy Procedia, vol. 112, 2017, pp. 314-321.

[6] CIGRE. Experiences in Service with New Insulating Liquids, 2010. [online] [08.03.2019]. Available at: http://static.mimaterials.com/midel/documents/sales/New_Experiences_in_Service_ with_New_Insulating_Liquids.pdf

[7] M\&I Materials Ltd. MIDEL 7131, 2019. [online] [10.03.2019]. Available at: https://www.midel.com/midel-range/midel-7131/

[8] Nadolny Z., Dombek G. Thermal properties of mixtures of mineral oil and natural ester in terms of their application in the transformer. E3S Web of Conferences, vol. 19, 2017, pp. 104-108.

[9] Dombek G., Nadolny Z. Measurements of the selected thermal properties of insulating liquids used in the high voltage power transformers. In Computer Applications in Electrical Engineering Measurements, 2013, pp. 189-198.

[10] SolidWorks Corporation, 2017. Solidworks.

[11] Mishra R. The Temperature Ratings Of Electronic Parts, 2004. [online] [15.03.2018]. Available at: https://www.electronics-cooling.com/2004/02/the-temperature-ratings-of-electronic-parts/

[12] NVIDIA Corporation. Nvidia GTX 980 specification, 2019. [online] [22.03.2019]. Available at: https://www.geforce.com/hardware/desktop-gpus/geforce-gtx-980/specifications 